\title{
Thoughts about Further Standardizing and Developing Model of Labor Dispatch Market
}

\author{
Shanshan $\mathrm{Xu}$ \\ School of Economics and Management \\ Shenyang Aerospace University, \\ Shenyang, China \\ E-mail: susan_xuss@hotmail.com
}

\begin{abstract}
The labor dispatch model is an important supplement to China's basic form of labor contract employment. After China's reform and opening up, companies which gain more autonomy in operation begin to take various ways to reduce labor costs, in order to meet the needs of market economy, thereby promoting such flexible employment method to be rapidly popularized in our country. In this thesis, the author makes a research on the labor dispatch mode, and tries to give advices on how to standardize and enrich employment forms in China, to promote flexible employment, then train and provide talents. Besides, he thinks that we should protect the interests of dispatched workers according to the law, because it will be of great significance for optimizing HR department in companies and promoting the development of labor dispatching.
\end{abstract}

Keywords-labor dispatch; emergence \& development; problems; solutions

\section{INTRODUCTION}

Labor dispatch is an employment pattern widely used in both developed and developing countries. In China, it is an important complement to labor contract, the basic form employment of enterprises. The emergence and development of labor dispatch promote the development of the labor market. Meanwhile, labor dispatch also has an important impact on human resource management in enterprises. To meet the needs of market economy, and solve the problems that currently exist in operations of labor dispatch, we shall standardize this form of employment, take appropriate measures to protect dispatched workers' rights and interests, to optimize the work of human resources department, and to further promote rapid development of this flexible labor dispatch in China.

\section{THE EMERGENCE \& DEVELOPMENT OF LABOR DISPATCH PROMOTES THE DEVELOPMENT OF THE LABOR MARKET}

Labor dispatch was originated in 1920 in the United States, created by Samuel Workman. At that time, Samuel Workman's company employed large numbers of women, taught them necessary skills, and then leased them to requiring enterprises to handle inventory work at night, meeting such temporary staff shortages.

During the 20 years from 1940 to 1960, this employment form was gradually spread throughout the world. Europe, Germany, France, Netherlands and Italy have set specific legislation on employment agencies. In 1978, labor dispatch was spread to Japan and got popularized. In the early 1990s, it firstly appeared in Beijing, Shanghai, Guangzhou, Shenzhen and other economically developed areas in China, and then rapidly expanded to other areas, becoming an important factor for promoting flexible employment. It plays a positive role for increasing jobs, promoting re-employment of unemployed persons, and meeting the special employing needs from different types of enterprises. After entering china, this model has been developing very fast, and the labor dispatch workers accounted for more and more percentage in overall employment numbers of enterprises year by year. A related survey shows that the total number of dispatched workers in China has reached over 60 million, accounting for $20 \%$ of the total number of domestic workers. Meanwhile, the labor dispatch shows a very prominent feature: fairly wide coverage of jobs and positions, from all types of enterprises to schools, hospitals and institutions. From the type of industries, the most dispatched workers $(43.6 \%)$ are in the manufacturing industry; from the type of ownership of employers, the most workers $(47.2 \%)$ are in the state-owned enterprises.

Labor dispatch is an employment model widely used in both developed and developing countries. In many countries around the world, there are laws and regulations about labor dispatch. Since situations in different countries or regions are different, often the definitions of labor dispatch also differ from each other. Therefore, before we talk further about labor dispatch, we shall determine its precise definition, which also has a direct and significant meaning for its development in China.

The term "labor dispatch" firstly appeared in 2002 in white paper "China's Employment Situation and Policies", and then also appeared in "Notice from CPC Central Committee State Council on Further Improving Re-Employment of Laidoff Workers ". The labor dispatch was officially defined in "Labor Contract Law" validating on January 1, 2008 as following: a dispatching party and an employing party sign a labor dispatch agreement; the dispatching party recruits workers and sends them to work for the employing party; the dispatched workers are led and supervised by the employing party to provide labor; the employing party pays money to the dispatching party in accordance with the agreement, while the dispatching party pays for the workers' wages, welfare and social insurance. 


\section{IMPACTS OF LABOR DISPATCH ON HR MANAGEMENT}

Flexible employment allows more flexible corporate strategy. In a market economy, it is very common that many employers adjust their main business out of own benefits or as seasonal changes, and naturally they will alter their needs for employees at any time. Otherwise, if they mechanically apply the original way of employment, they will probably encounter labor surplus or labor shortage in some temporary and unexpected work, which will disturb the plan and hinder the development of enterprises. Labor dispatch, on the other hand, can provide employers with a timely HR complement and flexible employment mechanism, which can effectively avoid the above problems. In needs of employment, employers can get workers in a short time simply by paying service fees to dispatchers. After the temporary employees finish their jobs, employers can either return them back to the dispatchers, or keep some of them as full-time staff, enabling more flexible HR strategy.

Reduced costs enable more smooth business operation. Firstly, under labor dispatch, the recruitment and training of staff are done by a third party, and employers only need issue their own specific demands, no need of labor- or humanconsuming large-scale recruitment, which to some extent, saves recruitment and training costs. Secondly, under labor dispatch mode, private enterprises need not directly manage the dispatched staff, only need check the results of their work; to be specific, enterprises do not have to consider job promotion and other aspects of personnel planning, nor spend a lot on personnel management, such as salary, archives, social security, or answering employees' daily questions, which saves management costs. In addition, private enterprises can also save the work of employee benefits, retirement arrangements and other matters, which will also promote cost savings.

Professional services enable enterprises to avoid employing risk. At present, China's enterprises are facing increasing risk in the employment process. For example, employers may blindly sign labor contracts without knowing the true level of hired talents, hiring process does not recognize of all causing a lot of economic and labor disputes. Statistics show that from January-September 2011, all levels of arbitration \& mediation units for labor disputes in China had accepted as many as 933,000 labor dispute cases. If enterprises adopt the labor dispatch model, then labor disputes will primarily handled by dispatching party who will negotiate with dispatched staff, so the above-mentioned risk can be effectively prevented in dispatch model to reduce losses to a minimum.

\section{PROBLEMS IN OPERATION OF LABOR DISPATCH}

Dispatch is not standardized. The modified Article 66 of Labor Law says, "Labor-contract employment is the basic employment form for companies in China. Labor dispatch, as a supplement form, can only be used on temporary, auxiliary or substitute job positions." Some enterprises, in order to avoid risks, sign dispatch agreements with their employees once a year, and sign labor contracts once every two years. Some companies even worse, in order to avoid trouble, sign multi- year agreements with employees, retaining them for future use, for unlike labor contracts, dispatch agreements need not be identified by the Bureau of Labor. However, these actions are prohibited in the new law.

HR products and services are limited. Some labor company only provides some limited HR services, which sometimes cannot meet the diverse needs of customers for service. For a long time, the labor dispatch products and services have always been the main (also core) business of some labor companies. However, this business model is easily copied by other companies. Besides, the newly revised "Labor Contract Law" gives further specifications on the labor dispatch and thus raises the requirements for labor service companies, so we can see the whole industry is facing new challenges.

The publicity for labor dispatch is not enough. Many labor companies do not have overall planning and initiative for publicity. As business scope expands, a company will surely become more impactive, but many companies do not realize the importance of wide publicity, they don't even have formal product brochures, and customers often have to ask whether they have other services.

Dispatched workers are not fully trained. Firstly, since employers are not responsible for staff recruitment, training, etc., it is difficult to directly know the staff's ability and to make full use of these staff in the talent management, which may cause a waste of talents. In addition, these staff can not be included in employers' talent development planning, which proposes challenges for personnel training. Secondly, since there is not direct labor relation between the employer companies and employees, the temporary employees may come and leave frequently. As a result, the employees will hardly have a sense of belonging, while the employers can hardly build a stable personnel team, which, to some extent, indirectly undermines the competitiveness of enterprises.

\section{SOLUTIONS FOR FURTHER STANDARDIZING AND DEVELOPING LABOR DISPATCH MARKET}

We should implement the newly revised "Labor Contract Law" to regulate the labor dispatch market. China's labor dispatch employment has been relatively "flexible" for a long time, while the newly revised "Labor Contract Law" mainly focused on addressing the abuse and irregularities of labor dispatch, and defines clearly that "labor contract employment is the basic employment form for companies in China, while labor dispatch is merely a supplement form. An employer shall pay dispatched workers the same salary as those contract workers on similar positions (in accordance with the principle of "equal pay"). With the implementation of the newly revised "Labor Contract Law", the society's growing concern about companies' social responsibility, and the rise of labor dispatch, labor outsourcing and other HR services, the cost of labor dispatch will increase, while competition in the market will become more intensive, which will certainly break the current market balance, and have a significant impact on HR services. Therefore, the dispatching companies shall make rational plans out of their own needs, in compliance with state laws and 
regulations, to pave the way for the finally legitimate employment and guarantee the freedom of workers to equal employment.

Promote innovation on HR services, focusing on industry guidance, policy support and environmental construction. Encourage the differential development, and develop all kinds of HR service products to meet the needs of different levels and types groups. Regulate the development of personnel agency, employee leasing, personnel training, labor dispatch and other HR services, encourage the development of HR outsourcing, HR management and consulting, and build new platforms of talent hunting, online recruitment, etc. for the overall HR outsourcing, to provide comprehensive, one-stop integrated HR services. Encourage HR agencies to 'go out' to provide HR services for Chinese enterprises exploring the international market.

Establish an internationally competitive HR services group. In the next 10 years, as China's HR industry is developing to brand-oriented and standardized level, HR development will be in the golden period of rapid growth, so there will be a re-shuffling process. Market demands are large enough to allow the formation of a huge space for development of HR industry. As a result, the existing labor companies shall stand on the basis of development in the past and give full play to the formed great advantages and influence in talents, network, experience, resources, brand and scale, to become one of the most competitive service companies in the field of HR services, and to establish a number of strong, influential, internationally competitive HR services groups through mergers, acquisitions, restructuring, alliances, etc.

Develop other expanded HR services and try restructuring toward outsourcing industry. After going into the "TwelfthFive-Year Plan", China's overall policy direction for development of the HR industry is to encourage emerging HR to develop toward outsourcing services, based on the specification of dispatch market. As the market continues to develop, especially after the newly revised "Labor Contract Law" becomes effective, labor companies will turn to a more regulated labor strategic road. Therefore, labor companies shall take this opportunity to make good use of existing client resources and market reputation, make efforts to expand the field of HR services to the outsourcing industry, such as providing training outsourcing, payroll outsourcing, recruitment outsourcing, process outsourcing and so on, and strive to become a leader the HR Service field, prepare for management consulting business, raise customer satisfaction, and increase their core competitiveness.

Intensify the publicity and actively expand customers. Enterprises shall have good publicity to establish social image, improve visibility and increase influence. It is especially important to further intensify the publicity and actively expand customers with the gradual expansion of business scale. Although solid quality of service is the foundation, good branding can let everyone know the company and raise improve the market competitiveness of enterprises, so the effective publicity is very important. In the current situation, we should focus on the expansion of customers to all kinds of fields, and promote new services to existing clients. At the same time, establish and improve the performance incentive system, and increase employees' initiative to expand customers. In addition, we shall use a full range of advocacy networks and make sure the effectiveness to give the greatest degree of publicity, such as setting official weibo, WeChat public account, Tencent QQ group and so on.

Improve the training on dispatched staff to enhance their overall quality. We shall hold regular training for staff to enhance their capacity of work and business, increase their sensitivity to policy changes and keep up with the development of enterprises. Meanwhile, some mental training can improve employees' self-confidence, completely changed the staff's views on the dispatch system and increase employees' sense of belonging to employers, which is good to the stability of personnel. We should also study how to switch from labor dispatch to labor outsourcing, change some of the dispatch services for customers into personnel agency. By doing such, together with labor dispute consultation and treatment, we can achieve the same effects as labor dispatch. This will not only meet the customers' requirements, but also to some extent on develop the labor companies' own business.

\section{REFERENCES}

[1] QU Kemin, "The knowledge Innovation and Human Resources," Chinese Academy of Social Sciences doctoral dissertation, pp. 55-76, 2001.

[2] ZHANG Xia, "Knowledge innovation of enterprise human resources management characteristics and mode innovation," Proc. Of the Journal of Huazhong University of Science and Technology, pp. 22-25, 2008(3).

[3] Andrew Smith, PeterJ.Dowling, "Analyzing Firm Training: Five Proposition for Future Research," Proc. Of the Human Resource Development Quarterly, Summer, pp.32-38, 2001(11).

[4] HAN Dayong, "Knowledge-based employee incentive strategy," Beijing, China Economic Press, pp.224-260, 2008.

[5] BAO Shuimei, LI Shiping, "Predicament and the root causes of our innovative talents training and the way out," Proc. Of the Modern education management, pp. 23-27, .2012(6).

[6] Q.LI, "Enterprise staff training effectiveness research," Master Dissertation of Southwestern University of Finance and Economics, pp.38-50, 2007.

[7] P.Sher, J.Lee, C.Vivid, "Information Technology As a Facilitator For Enhancing Dynamic Capabilities through Knowledge Management," Proc. Of the Information \& Management, pp.22-26, 2004(10). 